\title{
Hubungan Kamarisasi Dan Bahan Bakar Biomassa Terhadap Kejadian Infeksi Pernafasan Akut Pada Anak Balita
}

\section{Relationship Between Biomass Characterization And Fuel To The Arrival Events In Children}

\author{
Ricky Perdana Poetra*, Hj. Afriyana Amelia N.* \\ *STIKES Pelamonia Kesdam VII Wirabuana Makassar \\ email : rickyperdana_poetra@yahoo.com. \\ email : enho_cute78@yahoo.com
}

\begin{abstract}
ABSTRAK
ISPA merupakan penyakit infeksi saluran pernafasan yang masih merupakan masalah kesehatan yang serius terutama di negara-negara berkembang seperti di Indonesia. Tujuan penelitian ini adalah untuk mengetahui hubungan antara kamarisasi dan bahan biomassa terhadap kejadian penyakit ISPA pada anak balita di Kelurahan Kalebajeng, Kecamatan Bajeng, Kabupaten Gowa. Penelitian ini merupakan penelitian Survey Analitik dengan pendekatan Cross Sectional Study. Sampel adalah balita yang berada di Kelurahan Kalebajeng. Penarikan sampel menggunakan simple random sampling yaitu berjumlah 85 anak balita. Data diolah dengan menggunakan computer program SPSS dan dianalisis menggunakan uji chi square. Diperoleh hasil bahwa responden yang tidak memiliki kamar/memiliki kamar namun tidak memenuhi syarat sebanyak 22 orang (25,9\%), sedangkan yang memiliki kamar memenuhi syarat sebanyak 63 orang (74,1\%). Untuk ISPA menunjukkan bahwa dari 22 responden yang penggunaan kamarisasi tidak memenuhi syarat sebanyak 10 balita (45,5\%) yang menderita ISPA. Sedangkan dari 63 responden yang penggunaan kamarisasi memenuhi syarat sebanyak 49 balita $(75,0 \%)$ yang tidak menderita ISPA. Hasil uji statistik dengan menggunakan Yate's Correction di peroleh p-value $=0,070$ yang berarti p-value lebih besar dari alfa 0,05 dengan demikian H0 diterima. Artinya Tidak ada hubungan antara penggunaan kamarisasi dengan kejadian ISPA pada anak balita.
\end{abstract}

Kata Kunci : Ispa, Anak balita, Kamarisasi, Bahan bakar biomassa, Rumah sehat.

\section{ABSTRACT}

Acute respiratory tract infections are respiratory tract infections which are still a serious health problem, especially in developing countries such as Indonesia. The purpose of this study was to determine the relationship between chamberization and biomass material on the incidence of ISPA in children under five in Kalebajeng Village, Bajeng District, Gowa Regency. This research is an Analytical Survey research with the Cross Sectional Study approach. Samples are toddlers in Kel. Kalebajeng. Sampling using simple random sampling, which amounted to 85 children under five. Data was processed using SPSS program computer and analyzed using chi square test. It was found that 22 respondents (25.9\%) did not have a room / room but did not meet the requirements, while 63 people had a room (74.1\%). For ISPA shows that out of 22 respondents who use the chamberization did not meet the requirements as many as 10 toddlers (45.5\%) who suffer from ISPA. Whereas of the 63 respondents who used 
Ricky Perdana Poetra, Afriyana Amelia N : Hubungan Kamarisasi Dan ...

chamberization, there were 49 children (75.0\%) who did not suffer from ISPA. The results of statistical tests using Yate's Correction were obtained $p$-value $=0.070$, which means that p-value greater than alpha 0.05, thus HO is accepted. Meaning There is no relationship between the use of chamberization and the incidence of ISPA in children under five.

Keywords: Ispa, Toddlers, Kamarisasi, Biomass Fuel, Healthy Houses

\section{PENDAHULUAN}

Infeksi Saluran Pernapasan Akut (ISPA) merupakan pembunuh utama anak dibawah usia lima tahun (balita) di dunia, lebih banyak dibandingkan dengan penyakit lain seperti AIDS, malaria dan campak. Namun, belum banyak perhatian terhadap penyakit ini. Di dunia, dari 9 juta kematian balita, lebih dari 2 juta balita meninggal setiap tahun akibat pneumonia atau sama dengan 4 balita meninggal setiap menitnya. Dari lima kematian balita, satu diantaranya disebabkan pneumonia (Kemenkes RI, 2014).

Penyakit Infeksi Saluran Pernapasan Akut (ISPA) masih merupakan penyebab utama kesakitan dan kematian balita di Indonesia yaitu sebesar 28\%. WHO memperkirakan kematian akibat pneumonia mencapai 10\% sampai dengan 20\% pertahun dari seluruh jumlah bila tidak diberi pengobatan. Kematian balita karena pneumoni secara nasional diperkirakan 6 per 1000 balita per tahun atau sekitar 150.000 balita pertahun. Salah satu sasaran pemberantasan penyakit ISPA pada balita adalah menurunkan angka kematian balita akibat pneumonia (Kemenkes RI, 2015).

Di Indonesia berdasarkan hasil Riset Kesehatan Dasar (Riskesdas) tahun 2007, menunjukkan prevalensi nasional ISPA: 25,5\% (16 provinsi di atas angka nasional), angka kesakitan (morbiditas) pneumonia pada Bayi: 2.2\%, Balita: 3\%, angka kematian (mortalitas) pada bayi 23,8\%, dan Balita 15,5\% (Kemenkes RI, 2016).

Penyakit ISPA untuk daerah Kabupaten Gowa masih termasuk 10 besar penyakit paling mematikan yaitu menduduki peringkat pertama. Jumlah kasus penyakit pneumonia/ISPA untuk anak balita pada tahun 2018 di Kabupaten Gowa yaitu sebanyak 15.692 kasus. Jumlah ini telah mengalami penurunan dari tahun 2013 yang tingkat kejadiannya mencapai 17.000 kasus ISPA pada anak balita 
(Dinkes Kabupaten Gowa, 2018).

Data yang terhimpun untuk anak balita yang menderita ISPA di puskesmas Kecamatan Bajeng yaitu untuk kecamatan tahun 2018. Data yang di dapat yaitu 6 bulan pertama tahun 2017 terdapat 1772 kasus, dan terjadi penurunan pada 6 bulan terakhir tahun 2018 menjadi 1610 kasus. Sedangkan untuk Kelurahan Kalebajeng yaitu pada 6 bulan pertama tahun 2018 terdapat 161 kasus, dan terjadi penurunan pada 6 bulan terakhir tahun 2016 menjadi 112 kasus (Puskesmas Bajeng, 2018).

\section{METODE}

Desain penelitian ini menggunakan metode survai analitik dengan pendekatan cross sectional study dan observasi langsung yang dilaksanakan di Kelurahan Kalebajeng, Kecamatan bajeng, Kabupaten Gowa. Populasi dalam peneitian ini adalah anak balita yang berkunjung ke Puskesmas Bajeng 4 bulan terakhir sebanyak 109 balita. Tekhnik sampling yang digunakan yaitu dengan simple random sampling sehingga mendapatkan 85 sampel anak balita. Pengumpulan data yang dilakukan yaitu dari data sekunder dari puskesmas Bajeng dan data primer yang dilaksanakan melalui wawancara mendalam dengan instrument kuesioner, pengamatan langsung dengan instrument lembar observasi dan pengukuran langsung kamar balita dengan instrument alat ukur.

Variabel dependen adalah kejadian ISPA pada Anak Balita, yang diukur dengan cara melihat rekam medis di Puskesmas Bajeng, sedangkan variabel independent adalah kamarisasi yaitu pembagian ruangan di dalam rumah, karena apabila rumah tersebut tidak terdapat pembagian ruangan akan mudah terjadi penularan penyakit khususnya penyakit ISPA. Kategori memenuhi syarat kamarisasi yaitu bila ada kamar atau ruangan dalam rumah dengan luas kamar $8 \mathrm{~m}^{2} / 2$ orang. Untuk variabel independent kedua yaitu penggunaan bahan bakar biomassa di dalam rumah yang umumnya didapatkan pada bahan bakar dalam proses memasak yang mana akan menimbulkan polusi di dalam rumah. Kategori memenuhi syarat yaitu bila responden dalam kegiatan memasak menggunakan bahan bakar biomassa seperti minyak tanah dan kayu bakar. 
Ricky Perdana Poetra, Afriyana Amelia N : Hubungan Kamarisasi Dan ...

Pengolahan data dilakukan dengan komputer melalui program yang sesuai. Analisa data dilakukan dengan menguji hipotesa nol (Ho). Di uji dengan analisis univariat dan bivariat dengan chisquare yaitu Yate's Correction. Analisis data dilakukan secara elektronik dengan menggunakan komputer program SPSS (Statistical Package and Social Siences) dengan model analisis data yang dilakukan adalah analisis univariat dan bivariat. Data yang telah diolah disajikan dalam bentuk narasi kemudian diberikan uraian untuk melihat hubungan antara kamarisasi dan penggunaan bahan bakar biomassa terhadap kejadian ISPA pada anak balita di Kelurahan Kalebajeng.

\section{HASIL}

Berdasarkan hasil pengamatan dan pengukuran di lapangan, telah didapatkan beberapa hasil penelitian yang dilaksanakan di Kelurahan Kalebajeng, Kec. Bajeng, Kab. Gowa diperoleh informasi yaitu sebanyak 34 Responden dengan pendidikan SMA/Sederajat dan yang terendah adalah SD sebanyak 12 responden. Kategori umur yang terendah $\geq 50$ tahun yaitu sebanyak 3 responden. Mayoritas balita umur 48-49 bulan yaitu sebanyak 24 responden dan yang terendah memiliki kelompok umur 0-11 buln dan 12-23 bulan masing-masing sebanyak 10 responden. Mayoritas balita berjenis kelamin perempuan yaitu sebanyak 50 responden, dan yang memiliki jenis kelamin laki-laki sebanyak 35 responden.

Tabel 1 Hubungan Penggunaan Kamarisasi Dengan Kejadian ISPA Pada Balita Di Kelurahan Kalebajeng

\begin{tabular}{|c|c|c|c|c|c|c|c|}
\hline \multirow{3}{*}{$\begin{array}{c}\text { Penggunaan } \\
\text { Kamarisasi }\end{array}$} & \multicolumn{4}{|c|}{ Kejadian ISPA Pada Balita } & \multirow{3}{*}{$\mathrm{n}$} & \multirow{3}{*}{$\%$} & \multirow[t]{3}{*}{ PR (CI 95\%) } \\
\hline & \multicolumn{2}{|c|}{ Menderita } & \multicolumn{2}{|c|}{$\begin{array}{c}\text { Tidak } \\
\text { Menderita }\end{array}$} & & & \\
\hline & $\mathrm{n}$ & $\%$ & $\mathrm{n}$ & $\%$ & & & \\
\hline $\begin{array}{l}\text { Tidak memenuhi } \\
\text { syarat }\end{array}$ & 10 & 45,5 & 12 & 54,5 & 22 & 100,0 & \\
\hline Memenuhi syarat & 14 & 22,2 & 49 & 77,8 & 63 & 100,0 & 0.070 \\
\hline Total & 24 & 28,2 & 61 & 71,8 & 85 & 100,0 & \\
\hline
\end{tabular}


Tabel 1 diatas menunjukkan bahwa dari 22 responden yang penggunaan kamarisasi tidak memenuhi syarat sebanyak 10 balita (45,5\%) yang menderita ISPA. 63 responden yang penggunaan kamarisasi memenuhi syarat sebanyak 49 balita (75,0\%) yang tidak menderita ISPA.

Dari hasil uji statistic dengan menggunakan yate's Correction di peroleh $p$-value $=0,070$ yang berarti $p$-value lebih besar dari alfa 0,05 , dengan demikian $\mathrm{H}_{0}$ diterima dengan arti tidak ada hubungan antara kamarisasi dengan kejadian ISPA pada anak balita.

\section{Tabel 2 Hubungan Penggunaan Bahan Bakar Biomasa Dengan Kejadian} ISPA Pada Balita Di Kelurahan Kalebajeng

\begin{tabular}{|c|c|c|c|c|c|c|c|}
\hline \multirow{3}{*}{$\begin{array}{c}\text { Penggunaan Bahan Bakar } \\
\text { Biomasa }\end{array}$} & \multicolumn{4}{|c|}{ Kejadian ISPA Pada Balita } & \multirow{3}{*}{$\mathrm{n}$} & \multirow{3}{*}{$\%$} & \multirow{3}{*}{$\mathrm{p}$} \\
\hline & \multicolumn{2}{|c|}{ Menderita } & \multicolumn{2}{|c|}{$\begin{array}{c}\text { Tidak } \\
\text { Menderita }\end{array}$} & & & \\
\hline & $\mathrm{n}$ & $\%$ & $\mathrm{n}$ & $\%$ & & & \\
\hline Tidak menggunakan & 6 & 33,3 & 12 & 66,7 & 18 & 100,0 & \\
\hline Menggunakan & 18 & 26,9 & 49 & 73,1 & 67 & 100,0 & 0,805 \\
\hline Total & 24 & 28,2 & 61 & 71,8 & 85 & 100,0 & \\
\hline
\end{tabular}

Tabel diatas menunjukkan bahwa dari 18 responden yang penggunaan bahan bakar biomasa tidak memenuhi syarat sebanyak 6 balita (33,3\%) yang menderita ISPA. 67 responden yang penggunaan bahan bakar biomasa memenuhi syarat sebanyak 49 balita (73,1\%) yang tidak menderita ISPA. Dari hasil uji statistic dengan menggunakan Yate's Correction di peroleh $p$-value $=0,805$ yang berarti $p$-value > alfa 0,05 dengan demikian $\mathrm{H}_{0}$ diterima dengan artia tidak ada hubungan antara penggunaan bahan bakar biomasa dengan kejadian ISPA pada balita.

\section{PEMBAHASAN}

Rumah padat penghuni tiap-tiap anggota keluarga tidak semua mempunyai kamar sehingga kenyamanan akan terganggu, oleh karena itu pemisahan anggota keluarga baik dilakukan. Tidak adanya kamarisasi maka akan mempermudah penularan penyakit ISPA bila satu anggota keluarga menderita ISPA, terutama pada anak balita. Kondisi seperti ini sulit terwujud pada sebagian besar rumah responden Kelurahan Kalebajeng. Walaupun rata-rata mereka telah memiliki 
Ricky Perdana Poetra, Afriyana Amelia N : Hubungan Kamarisasi Dan ...

kamar akan tetapi masih jauh dari memenuhi syarat kesehatan.

Hal ini disebabkan oleh luas rumah yang tidak sebanding dengan jumlah penghuninya sehingga kebutuhan ruangan terutama untuk tempat tidur tidak dapat terpenuhi, akibatnya satu kamar yang seharusnya hanya ditempati oleh satu atau dua orang saja, terkadang ditempati lebih dari semestinya, bahkan ada rumah yang ukuran kamarnya berkurang dari standar namun terpaksa ditempati oleh beberapa orang.

Salah satu bahan bakar yang sebagian besar digunakan oleh masyarakat pedesaan adalah bahan bakar biomassa atau kayu bakar. Mengingat bahwa daerah pedesaan masih banyak hutan dan menghasilkan kayu sehingga masyarakat cenderung untuk menggunakan kayu atau sejenisnya untuk dijadikan sebagai bahan bakar, selain daripada itu bahan bakar ini sangat murah dan mudah. Tapi beranjak dari program pemerintah Kabupaten Gowa, telah dilaksanakan pembagian kompor gas dan gas gratis, sehingga sudah banyak pula yang menggunakan gas dan menjadikan bahanbakar biomassa sebgai alternatif lain.

Tingginya ISPA di sini salah satu penyebabnya karena dapur yang letaknya di dalam rumah, dimana paparan asap dapur yang menggunakan biomassa sangat berbahaya apabila terhirup oleh balita. Ada 2 bahan bakar biomassa yang digunakan oleh penduduk di Kelurahan Kalebajeng yaitu minyak tanah dan kayu bakar, dan sebagian besar telah menggunakan gas elpiji hasil dari pembagian dari program pemerintah.

\section{SIMPULAN}

Berdasarkan hasil penelitian yang dilakukan di Kelurahan Kalebajeng Kecamatan Bajeng Kabupaten Gowa, dapat disimpulkan sebagai berikut : Ada hubungan antara Kamarisasi dan Penggunaan Bahan Bakar Biomassa dengan kejadian ISPA pada anak balita di Kelurahan Kalebajeng, Kecamatan Bajeng, Kabupaten Gowa.

Saran Perlunya setiap keluarga membatasi kepadatan penghuni rumah untuk mencegah timbulnya berbagai penyakit terutama Infeksi Saluran Pernafasan Akut (ISPA), Kepada masyarakat dianjurkan agar memperhatikan kondisi 
perumahan terutama kamarisasi dan ruang dapur sehingga memenuhi syarat kesehatan untuk mencegah munculnya berbagai jenis penyakit khususnya penyakit Infeksi Saluran Pernafasan Akut (ISPA) pada anak balita,

\section{UCAPAN TERIMA KASIH}

Ucapan terima kasih penulis sampaikan kepada semua pihak yang membantu terlaksananya penelitian ini terutama dari Institusi STIKES Pelamonia Kesdam VII Wirabuana.

\section{DAFTAR PUSTAKA}

Aswar, Asrul. (2010). pengantar Ilmu kesehatan lingkungan, Mutiara Sumber Widya, Jakarta.

Budiyono, Marylin Junias. (2014). Pengaruh Faktor Fisik Rumah Adat Suku Dawan Terhadap Kejadian ISPA Pada Bayi. Jurnal Kesehatan Lingkungan Indonesia, (Online), Vol. 3, No. 1 April 2014, (http://artikel_Marylin.pdf, diakses 24 Maret 2018).

Cahaya, Nur. (2008). Faktor-Faktor Yang Berhubungan Dengan Kejadian ISPA di RSUD Barru Kabupaten Barru Tahun 2008. (Skripsi) Fakultas Kesehatan Masyarakat Universitas Indonesia Timur. Makasar

Kemenkes RI. (2014). Informasi tentang ISPA pada Anak Balita. Jakarta: Pusat Penyuluhan Kesehatan Masyarakat.

Kemenkes RI. (2016). Pneumonia Penyebab Kematian Utama Pada Balita, (Online), (Puskom.Depkes@Gmail.Com, diakses pada tanggal 27 Januari).

Kemenkes RI. (2015). Pedoman Pemberantasan Penyakit Infeksi Saluran Pernapasan Akut untuk Penanggulangan Pneumonia Balita, Jakarta.

Dinkes. (2016). Profil Kesehatan Kabupaten Gowa Tahun 2016.

Furtati, Jum. (2007). Faktor Risiko Yang Mempengaruhi Kejadian ISPA Pada Balita di Kelurahan Minasate'ne Kecamatan Pangkajene Kabupaten Pangkep, (skripsi) Fakultas Kesehatan Masyarakat UNHAS. Makasar

Mukono. (2006), Prinsip Dasar Kesehatan Lingkungan, Cet.VI; Surabaya: Airlangga University Press.

Noor, Bahry Noer. (2013). ISPA ancaman di musim pancaroba. Harian Fajar Makassar, hal. 6 tanggal 24 Maret, 2013.

Slamet, Juli Soemirat. (2012). Kesehatan Lingkungan, cetakan ke lima. Gadjah University Press, Bandung.

Suhandayani, Ike. (2006). Faktor-Faktor Yang Berhubungan Dengan Kejadian ISPA Pada Balita di Puskesmas Pati I Kabupaten Pati. Tesis tidak diterbitkan. Semarang. Fakultas Kesehatan Masyarakat. Universitas Negeri Semarang. 